\title{
Systemic oxidative stress in non-arteritic anterior ischemic optic neuropathy
}

\author{
Serife Birer ${ }^{1} \cdot$ Hatice Arda $^{2} \cdot$ Deniz Kilic $^{3} \cdot$ Gulden Baskol $^{4}$ \\ Received: 2 February 2018 / Revised: 22 January 2019 / Accepted: 12 February 2019 / Published online: 4 March 2019 \\ (c) The Royal College of Ophthalmologists 2019
}

\begin{abstract}
Purpose To investigate whether the serum total oxidant status (TOS), total antioxidant status (TAS), advanced oxidation protein products (AOPP), and thiol parameters could play a role in the pathogenesis of non-arteritic anterior ischemic optic neuropathy (NA-AION).

Methods In this study, 18 newly diagnosed NA-AION patients and 17 healthy subjects (control group) were included. Serum plasma TOS and TAS, AOPP, and thiol parameters were measured by spectrophotometric method and the results were compared.

Results Mean age of the patients and the controls were $60.8 \pm 8.4$ and $61.9 \pm 9.4$ years, respectively $(p=0.729)$. There were no significant differences between the patients and the control group with regard to the values of TAS, TOS, AOPP, and thiol $(p=0.869, p=0.863, p=0.040, p=0.314$; respectively). There was a positive correlation between TOS and thiol $(p=0.002, r=0.681)$.

Conclusion We found no significant relationship between systemic oxidative parameters and NA-AION. However, this study should be accepted as a pilot investigation and needs to be validated.
\end{abstract}

\section{Introduction}

Non-arteritic anterior ischemic optic neuropathy (NAAION) is the most common acute optic neuropathy in adults over the age of 50 years [1-3]. Sudden and painless vision loss in one eye is the main feature of NA-AION [4]. Several risk factors, such as age, systemic hypertension, diabetes mellitus, arteriosclerosis, hypercholesterolemia, nocturnal hypotension, obstructive sleep apnea, and a small optic cupto-disc ratio, have been reported [1, 4-8]. These pathological conditions lead to insufficient blood supply of the

Deniz Kilic

dnz_kilic@hotmail.com

1 Department of Ophtalmology, Kayseri Training and Research Hospital, Kayseri, Turkey

2 Department of Ophthalmology, Faculty of Medicine, Erciyes University, Kayseri, Turkey

3 Department of Ophtalmology, Develi State Hospital, Kayseri, Turkey

4 Department of Biochemistry, Faculty of Medicine, Erciyes University, Kayseri, Turkey optic nerve head due to some changes in the structure or function of the microcirculation [9].

In the human body, as a result of metabolic and physiological processes, some free oxygen radicals and oxidants are produced. Tissues have protective enzymatic and non-enzymatic antioxidative mechanisms for these radicals [10]. Increased oxidant formation or lowered antioxidants can initiate oxidative stress, damaging cell integrity and leading to cell death.

Oxidative damage is the result of oxidative insults due to the production of reactive oxygen and reactive nitrogen species generated by local ischemia [11]. Excessive free radicals in a cell can disrupt intracellular structures, including nucleic acids, lipids, and proteins $[12,13]$. Oxidative stress directly causes mitochondrial dysfunction, induction of apoptosis, increased neurotoxin production, weakening of the neuroprotective functions of glial cells, and activation of immune-mediated neuronal injuries [14]. Indeed, oxidative stress in retinal ganglion cells and retinal proteins may be the cause of optic disc deformities $[15,16]$. The contribution of oxidative stress to various ocular disorders is known [17]. Glaucoma, cataract, age-related macular degeneration, uveitis, and pterygium are some of those diseases [18-22]. 
Oxidative stress can be assessed by the oxidative status of biological samples. For prediction of oxidative stress, the measurement of total oxidant status (TOS), total antioxidant status (TAS), and advanced oxidation protein products (AOPP) are the most common parameters to test $[10,20]$.

In this study, we aimed to investigate the role of systemic oxidative stress in the pathogenesis of NA-AION.

\section{Patients and methods}

\section{Study population}

This prospective, case-control study was conducted at Erciyes University Hospital in Kayseri, Turkey and Institutional Review Board approved the methodology. The research protocol adhered to the tenets of the Declaration of Helsinki for clinical research. Written informed consent was obtained from all participants after explanation of the purpose and possible consequences of the study. Eighteen patients with a newly diagnosed NA-AION (NA-AION group) and 17 age-sex-matched healthy subjects (control group) were included in this study. The exclusion criteria were: smoking, presence of systemic diseases (diabetes, hypertension, renal or hepatic dysfunction), current antioxidant therapies, and any other ocular pathologies.

All patients underwent a detailed ophthalmological examination including best-corrected visual acuity (BCVA) measurement (Snellen charts), evaluation of relative afferent pupillary defect, color test using pseudo-isochromatic plates, intraocular pressure measurement with a Goldmann applanation tonometer (Haag-Streit Inc., Köniz, Switzerland), evaluation of anterior segment by slit-lamp biomicroscopy and fundus examination from dilated pupilla by slit-lamp biomicroscopy with $+90 \mathrm{D}$ lens, and examination of visual field by Octopus 900 perimetry (Haag-Streit Inc., Köniz, Switzerland).

Values of erythrocyte sedimentation rate and C-reactive protein of all the cases were recorded for differential diagnosis of arteritic anterior ischemic optic neuropathy and the patients who had increased values were excluded from the study. The diagnostic criteria for NA-AION include: (1) a history of sudden painless visual loss, (2) diffuse or sectoral optic disc edema, and (3) lack of any other systemic or ocular pathologies that could cause the similar symptoms.

\section{Blood sampling}

The blood samples obtained from patients (in the first 1-7 days after the symptoms were first seen) and controls were centrifuged for $5 \mathrm{~min}$ at $5000 \mathrm{rpm}$ (NF 400 centrifuges, Turkey). The plasma and serum of the samples were separated and kept at $-20{ }^{\circ} \mathrm{C}$ after being put in Eppendorf tubes.
Measurements were performed at the Erciyes University Medical Faculty Department of Biochemistry.

\section{AOPP measurement}

Plasma AOPP levels were determined by a spectrophotometric method (Shimadzu UV 1601 spectrophotometer, Shimadzu, Tokyo, Japan) using the method developed by Witko-Sarsat et al. [23]. The principle of the method is the oxidation of potassium iodide by long-lived chlorinated oxidants and protein cross-inding proteins in the plasma and the measurement of the resulting tri-iodide at $340 \mathrm{~nm}$.

\section{Thiol measurement}

Plasma thiol level was determined according to the method modified by $\mathrm{Hu}$ et al. [24]. The principle of the method is based on the spectrophotometric (Shimadzu UV 1601 spectrophotometer, Shimadzu, Tokyo, Japan) measurement, at a wavelength of $412 \mathrm{~nm}$, of the color intensity of the dark yellow 5-thio-2-nitrobenzoic acid that is produced as a result of the reduction by free thiol groups of the Ellman reactive [5.5'-dithiobis (2-nitrobenzoic acid)] as seen in the reaction equation.

\section{TOS measurement}

Erel developed a method to determine the serum TOS level [25]. In this method, the oxidants oxidize the ferrous ion-o-dianisidine complex to ferric ion. In acidic solution, the ferric ion and xylenol orange produce a colored complex. The color intensity is measured spectrophotometrically (Shimadzu UV 1601 spectrophotometer, Shimadzu, Tokyo, Japan). This intensity is proportional to the total amount of oxidant molecules. The assay is calibrated with hydrogen peroxide, and the results are expressed in terms of micromolar hydrogen peroxide equivalents per liter ( $m m o l ~ \mathrm{H}_{2} \mathrm{O}_{2}$ equivalent/L).

\section{TAS measurement}

Serum TAS levels were determined using the method developed by Erel [10]. According to this method, the Fenton reaction produces the most potent biological radical, hydroxyl radical. The reaction of the colorless substrate O-dianisidine and hydroxyl radicals produces the dianisyl radical, which has bright yellowish-brown color. A serum sample then added to the reaction mixture. The antioxidant components of the serum suppress the oxidative reactions initiated by the hydroxyl radicals. This suppression prevents the color change and provides an effective measure of the total antioxidant capacity of the serum. 


\section{Statistical analysis}

Statistical Package for the Social Sciences (SPSS ${ }^{\circ}$ ) 22.0 version on a Windows based PC was used for statistical analysis. In our study, "mean \pm standard deviation (SD)," "frequency" and "ratio" were used among the descriptive statistics. The distribution of variables was evaluated by Kolmogorov-Smirnov test. Quantitative values were compared between the two groups with $t$ test and MannWhitney $U$ test. The $\chi^{2}$ test was used for comparison of qualitative variables. Correlation analysis was performed using Spearman correlation coefficients. Bonferroni correction was performed for multiple comparisons and a $p$ value $<0.005$ was accepted as statistically significant.

\section{Results}

Mean ages for the NA-AION group and the controls were $60.8 \pm 8.4$ and $61.9 \pm 9.4$ years, respectively. The difference was not statistically significant $(p=0.729)$. There were 12 males and 6 females in the NA-AION group and 12 males and 5 females in the control group. AOPP values were higher in NA-AION group $(281.8 \pm 126.6 \mu \mathrm{mol} / \mathrm{L})$ than in the controls $(209.6 \pm 59.8 \mu \mathrm{mol} / \mathrm{L})$ but this difference failed to reach a significant level $(p=0.040)$ (Fig. 1). There was no significant difference between the NA-AION group and controls with regard to the values of TAS, TOS, and thiol ( $p=0.869,0.863$, and 0.314 , respectively). Mean values of AOPP, TAS, TOS, and thiol are shown in Table 1. A positive correlation was found between the values of TOS and thiol $(p=0.002, r=0.681)$. There was no correlation between the visual acuity and the parameters of TAS, TOS, AOPP, and thiol.

\section{Discussion}

The pathogenesis of NA-AION is poorly understood. However, it is believed that NA-AION is caused by vascular insufficiency resulting from disturbed small-vessel autoregulation of the posterior ciliary circulation that leads to optic nerve head $(\mathrm{ONH})$ ischemia [26]. Under normal conditions, blood flow is autoregulated and maintained at a relatively constant level in the retina and $\mathrm{ONH}$. A number of factors released by the vascular endothelium, including endothelin-1 and nitric oxide, are suggested to play an important role in the regulation of local perfusion in the retina and ONH [27]. Glaucoma is a kind of optic neuropathy, like NA-AION and ischemia is a precursor of both glaucoma and NA-AION. Vascular dysfunction that causes ischemia in the optic nerve is one of the possible mechanisms that have been postulated as causative for primary

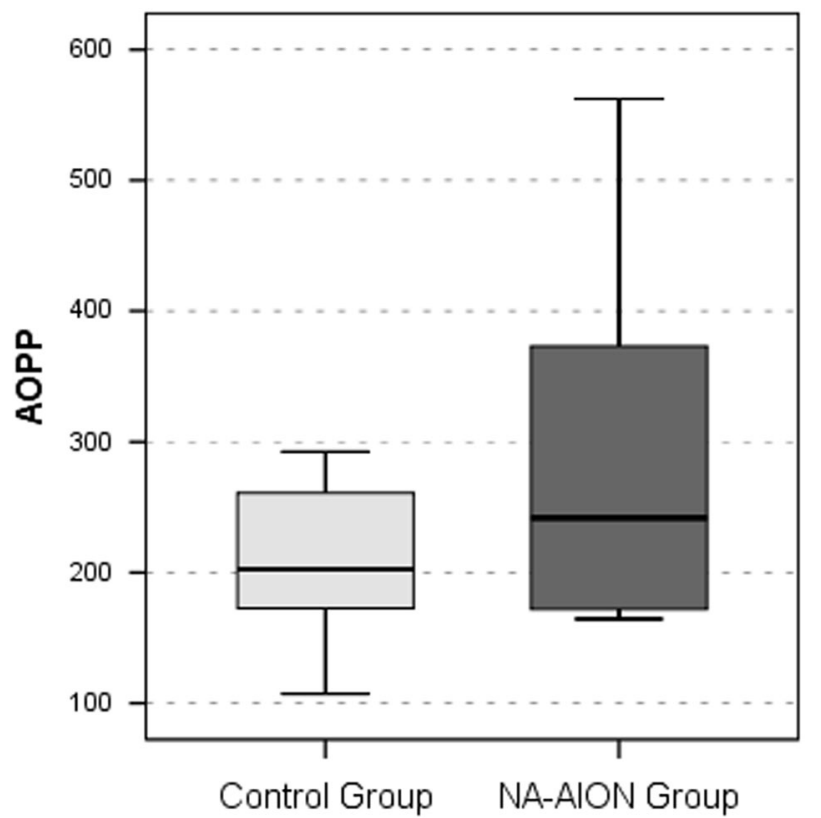

Fig. 1 Advanced oxidation protein productvalues

Table 1 Mean \pm SD values of AOPP, TAS, TOS, and thiol

\begin{tabular}{lccc}
\hline & $\begin{array}{l}\text { NA-AION group } \\
(\text { Mean } \pm \text { SD) } \\
n=18\end{array}$ & $\begin{array}{l}\text { Control group } \\
(\text { Mean } \pm \text { SD }) \\
n=17\end{array}$ & $p$ Value $^{\text {a }}$ \\
\hline AOPP & $281.8 \pm 126.6$ & $209.6 \pm 59.8$ & 0.040 \\
TAS & $0.9 \pm 0.4$ & $0.9 \pm 0.2$ & 0.869 \\
TOS & $6.20 \pm 2.0$ & $6.2 \pm 2.6$ & 0.863 \\
Thiol & $252.9 \pm 59.9$ & $273.9 \pm 93.7$ & 0.314 \\
\hline
\end{tabular}

$A O P P$ advanced oxidation protein product, TOS total oxidant status, TAS total antioxidant status

${ }^{a}$ Mann-Whitney $U$ test with Bonferroni correction, $p<0.005$ accepted as statistically significant

open angle glaucoma (POAG). Chronic impairment of the blood supply in the ONH causes ganglion cell damage [28, 29]. Ferreira et al. [21] aimed to establish the antioxidant status of the aqueous humor of patients with POAG. They reported that the total reactive antioxidant potential was significantly decreased by $64 \%$ in glaucoma patients.

Oxidative stress can be defined as an increase in oxidants and/or a decrease in antioxidant capacity leading to an excess of molecules containing free radicals such as reactive oxygen species (ROS) and reactive nitrogen species in any cells or tissues of the human body [30, 31]. Although previous studies investigated oxidative stress in various ocular disorders such as glaucoma, cataract, and age-related macular degeneration, the systemic oxidative status of patients with NA-AION was not investigated previously [18-21]. 
Balci et al. showed the role of oxidative stress in the ethiopathogenesis of pterygium by measuring oxidative markers in pterygium tissue samples [22]. In our study, it was difficult to obtain tissue samples from the optic nerve or retina because of the ethical problems of invasive techniques. Therefore, we investigated whether increased serum oxidant/antioxidant status levels and oxidative stress markers play a role in the pathogenesis in NA-AION. In further postmortem studies or histopathological studies of these tissues, the local oxidative stress and its products could be analyzed in NA-AION patients.

Toprak et al. found increased serum TAS and TOS in keratoconus. They concluded that systemic oxidative stress has an effect on the pathogenesis of keratoconus. They also mentioned that these markers indicate the cumulative action of antioxidants and oxidants [32]. This could be the reason why our results were not similar. Oxidant status and antioxidant status should be measured simultaneously to assess oxidative stress more exactly.

In contrast to our study, a previous study found that serum AOPP levels were decreased in glaucoma patients, whereas other serum oxidative markers were increased [33]. We suggest that there are other molecular pathways of glaucoma pathogenesis different from NA-AION.

On the other hand, as in our study, Baskol et al. investigated serum AOPP levels and found them to be increased in patients who have diabetic retinopathy compared to controls. They also measured total thiol as a marker of antioxidant status. The levels were higher but not statistically significant [34]. We found a positive correlation between TOS and thiol levels. Since thiol is known as a strong antioxidant [35], this positive correlation may be due to antioxidant compensation in response to change in oxidant status.

Oxidative protein damage is the result of oxidative insults due to the production of ROS and reactive nitrogen species generated by local ischemia. Accordingly, such increases in oxidative protein damage can affect cellular integrity [11]. It is well known that repeated chronic oxidative stress caused by reperfusion leads to the loss of the retinal ganglion cells [36]. Ischemia-induced oxidative stress can damage both the retina and optic nerve [37].

Protein oxidation products are also important signs of oxidative stress. It has been shown that there is a strong correlation between the disease progression and protein oxidation. AOPP is produced during oxidative stress. AOPP level is used as a measure of protein oxidation. In our study, the AOPP level was non-significantly high [33].

There are also a vast number of methods that are not mentioned in our study, have been developed, and used in virtually all diseases to measure the extent and nature of oxidative stress. One of them is serum malondialdehyde (MDA), the end product of the significant oxidation of lipids [31]. Since the retina and optic nerve is rich in lipid, it is a limitation of our study not to assess MDA levels in NA-AION patients. Nevertheless, in a recent review, Frijhoff et al. discussed the status of oxidative stress biomarkers as clinical diagnostics. They found that, in the current literature even when the highest evidence level is available, their specificity as a biomarker of oxidative stress could be questionable. They also mentioned that one biomarker is not necessarily better than others [38].

Various antioxidative defense mechanisms have evolved to protect cells from oxidative damage [39, 40]. However, some structural abnormalities resulting from excessive oxidative stress may be related to the overload of physiologic defense mechanisms [41]. The use of antioxidants for the prevention of glaucomatous deterioration has been addressed [29]. These treatments may also be useful especially for preventing optic nerve pathologies in patients who are under risk for NA-AION.

In conclusion, although previous studies demonstrated that oxidative stress has a role in the pathogenesis of many ocular pathologies, this study evaluated the systemic oxidative and antioxidative status and the AOPP level of the patients with NA-AION. We found no significant relationship between oxidative biomarkers and NA-AION, although our findings need to be confirmed by further studies in a larger population.

\section{Summary}

\section{What was known before}

- Previous studies investigated systemic oxidative stress in various ocular disorders, such as glaucoma, cataract, age-related macular degeneration, diabetic reitnopathy, uveitis, and keratoconus.

- The effect of systemic oxidative stress in patients with NA-AION was not investigated previously.

\section{What this study adds}

- In patients with NA-AION, plasma AOPP, TAS, TOS, and thiol levels were not significantly different when compared with those of the healthy subjects.

- This investigation might be considered as a pilot study about the presence of oxidative stress in pathogenesis of NA-AION.

\section{Compliance with ethical standards}

Conflict of interest The authors declare that they have no conflict of interest. 
Publisher's note: Springer Nature remains neutral with regard to jurisdictional claims in published maps and institutional affiliations.

\section{References}

1. Rucker JC, Biousse V, Newman NJ. Ischemic optic neuropathies. Curr Opin Neurol. 2004;17:27-35.

2. Hattenhauer MG, Leavitt JA, Hodge DO, Grill R, Gray DT. Incidence of nonarteritic anterior ischemic optic neuropathy. Am J Ophthalmol. 1997;123:103-7.

3. Johnson LN, Arnold AC. Incidence of nonarteritic and arteritic anterior ischemic optic neuropathy. Population-based study in the state of Missouri and Los Angeles County, California. J Neuroophthalmol. 1994;14:38-44.

4. Buono LM, Foroozan R, Sergott RC, Savino PJ. Nonarteritic anterior ischemic optic neuropathy. Curr Opin Ophthalmol. 2002;13:357-61.

5. Newman NJ, Scherer R, Langenberg P, Kelman S, Feldon S, Kaufman D, et al. The fellow eye in NAION: report from the ischemic optic neuropathy decompression trial follow-up study. Am J Ophthalmol. 2002;134:317-28.

6. Hayreh SS. Acute ischemic disorders of the optic nerve: pathogenesis, clinical manifestations, and management. Ophthalmol Clin North Am. 1996;9:407-42.

7. Newman NJ, Dickersin K, Kaufman D, Kelman S, Scherer R. Characteristics of patients with non arteritic anterior ischemic optic neuropathy eligible for the Ischemic Optic Neuropathy Decompression Trial. Arch Ophthalmol. 1996;114:1366-74.

8. Arnold AC. Pathogenesis of nonarteritic anterior ischemic optic neuropathy. J Neuroophthalmol. 2003;23:157-63.

9. Palombi K, Renard E, Levy P, Chiquet C, Deschaux Ch, Romanet $\mathrm{JP}$, et al. Non-arteritic anterior ischaemic optic neuropathy is nearly systematically associated with obstructive sleep apnea. Br J Opthalmol. 2006;90:879-82.

10. Erel O. A novel automated method to measure total antioxidant response against potent free radical reactions. Clin Biochem. 2004;37:112-9.

11. Friguet B. Protein repair and degradation during aging. Sci World J. 2002;2:248-54.

12. Cance B, Sies H, Boveris A. Hydroperoxide metabolism in mammalian organs. Physiol Rev. 1979;59:527-605.

13. Davies KJA. Protein damage and degradation by oxygen radicals. J Biol Chem. 1987;262:9902-7.

14. Flammer J, Mozaffarieh M. What is the present pathogenetic concept of glaucomatous optic neuropathy? Surv Ophthalmol. 2007;52:162-73.

15. Liu Q, Ju WK, Crowston JG, Xie F, Perry G, Smith MA, et al. Oxidative stress is an early event in hydrostatic pressure-induced retinal ganglion cell damage. Invest Ophthalmol Vis Sci. 2007; 48:4580-9.

16. Garcia-Valenzuela E, Shareef S, Walsh J, Sharma SC. Programmed cell death of retinal ganglion cells during experimental glaucoma. Exp Eye Res. 1995;61:33-44.

17. Ocakoglu O, Balcı H, Ozkök A, Dinçer Y, Koç EE, Uçar D, et al. Primer açık açılı glokomlu ve senil kataraktlı hastalarda oksidatif stresin rolü. T Oft Gaz. 2008;38:292-7.

18. Bokov A, Chaudhuri A, Richardson A. The role of oxidative damage and stress in aging. Mech Ageing Dev. 2004;125:811-26.

19. Moriarty-Craige SE, Adkinson J, Lynn M, Gensler G, Bressler S, Jones DP, et al. Antioxidant supplements prevent oxidation of cysteine/cystine redox in patients with age-related macular degeneration. Am J Ophthalmol. 2005;140:1020-6.
20. Zoric L, Miric D, Milenkovic S, Jovanovic P, Trajkovic G. Pseudoexfoliation syndrome and its antioxidative protection deficiency as risk factors for age-related cataract. Eur J Ophthalmol. 2006;16:268-73.

21. Ferreira SM, Lerner SF, Brunzini R, Evelson PA, Llesuy SF. Oxidative stress markers in aqueous humor of glaucoma patients. Am J Ophthalmol. 2004;137:62-69.

22. Balci M, Sahin S, Mutlu FM, Yagci R, Karanci P, Yildiz M. Investigation of oxidative stress in pterygium tissue. Mol Vision. 2011;17:443-7.

23. Witko-Sarsat V, Friedlander M, Capeillère-Blandin C, NguyenKhoa T, Nguyen AT, Zingraff J, et al. Advanced oxidation protein products as a novel marker of oxidative stress in uremia. Kidney Int. 1996;49:1304-13.

24. Hu ML, Loue S, Cross CE, Motchnik P, Halliwell B. Antioxidant protection against hypochlorous acid in human plasma. J Lab Clin Med. 1993;121:257-62.

25. Erel O. A new automated colorimetric method for measuring total oxidant status. Clin Biochem. 2005;38:1103-11.

26. Beri M, Klugman M, Kohler J, Hayreh SS. Anterior ischemic optic neuropathy. Ophthalmology. 1987;94:1020-8.

27. Venkataraman ST, Flanagan JG, Hudson C. Vascular reactivity of optic nerve head and retinal blood vessels in glaucoma - a review. Microcirculation. 2010;17:568-81.

28. Flammer J. The vascular concept of glaucoma. Surv Ophthalmol. 1994;38:3-6.

29. Hayreh S. Factors influencing blood flow in the optic nevre head. J Glaucoma. 1997;66:412-25.

30. Horoz M, Bolukbas C, Bolukbas FF, Aslan M, Koylu AO, Selek $\mathrm{S}$, et al. Oxidative stress in hepatitis $\mathrm{C}$ infected end-stage renal disease subjects. BMC Infect Dis. 2006;6:114.

31. Kersten E, Paun CC, Schellevis RL, Hoyng CB, Delcourt C, Lengyel I, et al. Systemic and ocular fluid compounds as potential biomarkers in age-related macular degeneration. Surv Ophthalmol. 2018;63:9-39.

32. Toprak I, Kucukatay V, Yildirim C, Kilic-Toprak E, Kilic-Erkek $\mathrm{O}$. Increased systemic oxidative stress in patients with keratoconus. Eye. 2014;28:285-9.

33. Engin KN, Yemisci B, Yigit U, Agachan A, Coskun C. Variability of serum oxidative stress biomarkers relative to biochemical data and clinical parameters of glaucoma patients. Mol Vis. 2010;16: 1260-71.

34. Baskol G, Gumus K, Oner A, Arda H, Karakucuk S. The role of advanced oxidation protein products and total thiols in diabetic retinopathy. Eur J Ophthalmol. 2008;18:792-798.34.

35. Schafer FQ, Buettner GR. Redox environment of the cell as viewed through the redox state of the glutathione disulfide/ glutathione couple. Free Radic Biol Med. 2001;30:1191-212.

36. Flammer J. Glaucomatous optic neuropathy: a reperfusion injury. Klin Mon Augenheilkd. 2001;218:290-1.

37. Kim JM, Kim YJ, Kim DM. Increased expression of oxyproteins in the optic nerve head of an in vivo model of optic nerve ischemia. BMC Ophthalmol. 2012;5:12. 63

38. Frijhoff J, Winyard PG, Zarkovic N, Davies SS, Stocker R, Cheng $\mathrm{D}$, et al. Clinical relevance of biomarkers of oxidative stress. Antioxid Redox Signal. 2015;23:1144-70.

39. Halliwell B, Gutteridge JMC. Role of free radicals and catalytic metal ions in human diseases: an overview. Methods Enzymol. 1990;186:1-85.

40. Stadtman ER. Protein oxidation and aging. Science. 1992;257: 1250-8.

41. Mozaffarieh M, Grieshaber MC, Flammer J. Oxygen and blood flow: players in the pathogenesis of glaucoma. Mol Vis. 2008; 14:224-33. 